\title{
Care Situation for Female Victims of Sexual Violence in Metropolitan Emergency Departments with Charité/Berlin as an Example
}

\author{
Versorgungssituation von weiblichen Opfern sexualisierter Gewalt \\ in großstädtischen Notfallambulanzen am Beispiel Charité/Berlin
}

Authors

Affiliations
H. Hoffmann-Walbeck ${ }^{1}$, M. Möckel ${ }^{2}$, S. Etzold ${ }^{3}$, M. David ${ }^{4}$

The affiliations are listed at the end of the article.

\section{Key words \\ - sexual violence \\ - initial treatment \\ - stuprum kit \\ Schlüsselwörter \\ - sexualisierte Gewalt \\ - Erstversorgung \\ - Stuprum}

Deutsche Version unter: http://dx.doi.org/ $10.1055 / \mathrm{s}-0042-113187$

received $\quad 11.4 .2016$ revised 21.7.2016 accepted 21.7.2016

\section{Bibliography}

DOI http://dx.doi.org/

10.1055/s-0042-113187

Geburtsh Frauenheilk 2016; 76: 1180-1185 @ Georg Thieme Verlag KG Stuttgart · New York . ISSN 0016-5751

\section{Correspondence}

Prof. Dr. med. Matthias David Charité Universitätsmedizin Berlin

Campus Virchow-Klinikum

Klinik für Gynäkologie

Augustenburger Platz 1

13353 Berlin

matthias.david@charite.de

\section{Abstract}

$\nabla$

Introduction: Sexual violence to females is a major health-care problem world-wide. To better care for the victims of sexual violence a "stuprum kit" was developed in 2010 by an interdisciplinary team in Berlin and its utility and acceptance are now evaluated two and a half years after its introduction in the departments of emergency medicine of the Charité.

Methods: In a retrospective case analysis, the data of all female patients aged 16 years or more who were cared for between 01.01.2011 and 31.12.2012 using the "stuprum kit" after a police report of a sexual crime in one of the departments of emergency medicine of the Charité were evaluated. The evaluation encompassed the medical findings form (MFF) of the kit as well as surveys of the medical and nursing staff using a standardised questionnaire.

Results: 270 patients with an average age of 30 years (min./max. 16-92 years) were included in the study. Most of the perpetrators were strangers $(50 \%), 1 / 4$ of the perpetrators were friends or relations; $17 \%$ were (ex-)partners. The waiting time in the Charite emergency departments amounted to 58 minutes on average, the medical treatment time 55 minutes. About $80 \%$ of the personnel evaluated the "stuprum kit" as being altogether good or very good. More than $1 / 3$ considered the time and room conditions as being unsuitable or rather unsuitable for the situation. Two thirds expressed the desire for further training and supervision.

Conclusion: The structured procedure by means of the "stuprum kit" has proved its value. A need for optimisation was seen especially for the examination facilities in the emergency departments.

\section{Zusammenfassung \\ $\nabla$}

Einleitung: Sexualisierte Gewalt gegen Frauen stellt weltweit ein großes gesundheitspolitisches Problem dar. Zur besseren Versorgung von Opfern sexualisierter Gewalt wurde 2010 in Berlin interdisziplinär ein „Stuprum-Kit“ entwickelt, dessen Anwendbarkeit und Akzeptanz 21/2 Jahre nach Einführung in den Charité-Rettungsstellen bewertet werden sollen.

Methoden: In einer retrospektiven Fallanalyse werden die Daten von allen Patientinnen > 16 Jahren, die zwischen 01.01.2011 und 31.12.2012 nach einer polizeilichen Anzeige einer Sexualstraftat mittels des „Stuprum-Kit“ in einer der 3 Charité-Rettungsstellen versorgt wurden, ausgewertet. Die Auswertung umfasst den Ärztlichen Befundbogen (ÄBB) des Kit sowie eine Personalbefragung des ärztlichen und pflegerischen Personals der Rettungsstellen mittels standardisierter Fragebögen.

Ergebnisse: In die Studie gingen 270 Patientinnen mit einem Altersdurchschnitt von 30 Jahren ein (Min./Max. 16-92 Jahre). Die meisten Täter waren den Patientinnen zuvor unbekannt (50\%), 1/4 der Täter kam aus dem Bekannten-/Freundeskreis; 17\% waren (Ex-)Partner. Die Wartezeit in der Charité-Rettungsstelle betrug im Mittel $58 \mathrm{~min}$, die ärztliche Behandlungszeit $55 \mathrm{~min}$. Etwa $80 \%$ des Personals bewertete das „Stuprum-Kit“ als insgesamt gut bis sehr gut. Zeitliche und räumliche Untersuchungsbedingungen wurden von über $1 / 3$ als nicht/eher nicht situationsangemessen befunden. Zwei Drittel wünschten Fortbildung und Supervision.

Schlussfolgerung: Das strukturierte Verfahren mittels „Stuprum-Kit“ hat sich bewährt. Optimierungsbedarf wurde insbesondere bei den äußeren Untersuchungsbedingungen in der Rettungsstelle gesehen. 


\section{Introduction}

\section{$\nabla$}

Sexual violence to women is an important factor in health-care for women with a wide-reaching and much underestimated impact on health. Long-term mental sequelae after sexual violence often result in a loss of self-confidence, feeling of vulnerability, state of panic, sleeping disorders, shame, feelings of guilt, posttraumatic stress disorder, self-injury and depression through to suicidal thoughts [1-6]. Also, diverse somatic and psychosomatic after effects have been described. For example, women who have experienced violence are affected more often by various gynaecological complaints than women who have not suffered from sexual violence [1,7]. Experience of violence apparently favours health-damaging behaviour. On average, abused women report higher alcohol, drug and nicotine abuse than women who have not experienced violence $[1,4]$.

A comparison of crimes against sexual self-determination in the international context is difficult due to the different definitions of sexual violence, the respective legal situations and the way different societies handle it. The actual prevalence of sexual violence is not definitively known because of the large number of unrecorded cases. In so-called victimisation studies, an attempt is made to determine the incidence of sexual violence in a region by means of representative questionnaires. In one such study carried out by the EU in 28 member countries, on average $11 \%$ of all women had at least once been a victim of sexual abuse since their 15th birthday [8].

A crime against sexual autonomy is a major interference in the physical and mental integrity of the respective victim. After the loss of control over the situation and one's own body, it is important to avoid a "secondary victimisation" by what could be perceived as a demeaning questioning and examination. The competent management of the victim by trained personnel can contribute to a stabilisation of their condition and work against consequential psychosocial damage [9]. The recognition of the suffering experience as well as the management of physical and mental concerns are usually the most important factors for the afflicted women [8-11]. Besides the necessary, medical and psychological care for victims of sexual abuse, a court-proof documentation of injuries with a detailed and neutral description of the findings are necessary as foundation for an expert assessment. If at all possible this should be acquired within 24 hours after the assault, at the latest within a period of $<72 \mathrm{~h}$, in order to collect and preserve possible DNA traces of the perpetrator.

For a standardised and court-proof examination and the securing of evidence, so-called examination kits are used, these contain the necessary materials for securing evidence and treatment guidelines. In the Charité University School of Medicine in 2010, an interdisciplinary team developed such an examination kit including a medical documentation form and action guidelines for the care of victims of sexual violence and, after a pilot phase, introduced it in the emergency departments of the Charité. The aim of this study is to assess the utility of the "Charite stuprum kit", to seek possibilities for optimisation with regard to patientcentred management and to judge its acceptance by the professional staff.

\section{Patients, Materials and Methods}

\section{$\nabla$}

Patient collective

Included in this retrospective case analysis were all women over the age of 16 years who had undergone a standardised examination in the period between 01.01.2011 through to 31.12.2012 in one of the three emergency departments of the Charite Berlin (Campus Benjamin Franklin, Campus Charité Middle or Campus Virchow Clinic) as a consequence of a police report of sexual violence.

\section{Materials and methods}

This study is based on an evaluation of the medical findings forms (MFF) as component of the "Charité stuprum kit", the socalled first-aid certificate (documentation of primary medical care in the emergency room) and a personnel survey on the practicality of the "Charité stuprum kit". The MFF consists of six pages. Data of the victim, the name of the examining physician as well as the time and place of the examination are documented. In addition, details of the medical history such as, e.g., drugs prescribed and taken, pregnancies, contraception and hepatitis $B$ and tetanus vaccinations are recorded. The following details of the incident (place, time and nature of assault) can be given as free texts. Examination and collection of evidence are divided into six sections. For each section the examination kit contains a labelled package unit with the appropriate securing means. For the data analysis 33 items were acquired. The physical injuries to the patient as documented by the physician were retrospectively categorised according to the modified criteria of the "clinical injury score" according to McGregor et al. [12].

In the emergency department a first-aid certificate is made out for each and every patient. Further details about the patient as well as admission and discharge times are entered here.

Since not only ethical but also practical reasons do not allow an additional questioning of the patients, two items recorded in the MFF are used as surrogate parameters of patient satisfaction (firstly, short waiting time for the patient; secondly, examination by female physicians).

The total concept of the "stuprum kit" and the examination conditions in the emergency departments as well as suggestions for improvements have been evaluated by means of surveys among the involved personnel. These surveys with the personnel of the three emergency departments of the Charite took place in the first quarter of 2013. After consultations and with the approval of the staff council and the data protection officers of the Charité, self-developed questionnaires were distributed among the nursing staff of the emergency departments and the physicians of the gynaecological departments who were responsible for the examinations and care of patients using a stuprum report. These questionnaires contained items on field of activity, gender, and professional experience of the recipients. Personal opinions of various aspects of the care situation (measured with five- or four-point ordinal scales) were addressed in eight questions. In two of the questions concrete criticisms could be expressed as free texts. These answers were sorted into thematic groups for the evaluation.

All data sets were recorded in Microsoft Excel tables and descriptively processed using IBM SPSS Statistics 22. The data were stored and processed according to the directives of the Charités data protection officers and subject to the GCP guidelines. Routine data were used exclusively. 
Table 1 Details about the scene of the crime and relationship to the suspected perpetrator as reported by the attacked women $(n=270)$.

\begin{tabular}{|lrr|}
\hline Scene of the crime & n & \multicolumn{1}{l}{$\%$} \\
\hline Entire private sphere & 182 & $67.2 \%$ \\
\hline - victim's own home & 75 & $27.7 \%$ \\
\hline - perpetrator's home & 70 & $26.2 \%$ \\
\hline - common dwelling & 9 & $3.3 \%$ \\
\hline - home of third party & 10 & $3.7 \%$ \\
\hline - hotel, pension & 9 & $3.3 \%$ \\
\hline - private car & 7 & $3.0 \%$ \\
\hline Entire public sphere & 73 & $26.9 \%$ \\
\hline - public place & 32 & $11.4 \%$ \\
\hline publicly accessible building & 29 & $10.7 \%$ \\
\hline - hallway, cellar, court yard & 6 & $2.2 \%$ \\
\hline - public transport, taxi & 4 & $1.5 \%$ \\
\hline patient's working place & 3 & $1.1 \%$ \\
\hline - no information & 16 & $5.9 \%$ \\
\hline Relationship victim-suspected perpetrator & & \\
\hline - stranger & 135 & $50.0 \%$ \\
\hline - friend/acquaintance & 46 & $17.0 \%$ \\
\hline - partner/ex-partner & 68 & $25.2 \%$ \\
\hline - fleeting acquaintance & 8 & $3.0 \%$ \\
\hline - family member & 3 & $1.1 \%$ \\
\hline - no information & 10 & $3.7 \%$ \\
\hline
\end{tabular}

\section{Results}

$\nabla$

\section{Patient collective}

In the course of the present study, data from 270 patients who presented to the Charité emergency departments after police reports as victims of sexual violence in the period from January 2011 to December 2012 and were examined with the help of the "stuprum kit". The ages of the patients ranged between 16 and 92 years (average age: 30 years). The medical findings forms (MFF) as components of the so-called stuprum kit were complete in 97\% (262/270). Eight forms did not include all the necessary details.

\section{Time point of presentation to the emergency}

department

Two thirds of the patients came to one of the three Charité emergency departments for examination and treatment within 24 hours after the assault. $24.1 \%$ of the women presented between 0.00 and 8.00 o'clock, $37.4 \%$ and $38.5 \%$, respectively, between 8.00 and 16.00 and 16.00 and 24.00. The case number was highest in June (35/270, 13\%) and lowest in November (14/ $270,5.2 \%)$. In most of the cases the reported assault took place at the weekend; $26.3 \%(71 / 270)$ on Saturdays and $18.9 \%$ (51/ 2710) on Sundays.

\section{Details of the offence}

Most of the perpetrators were strangers to the patients (50\%), $1 / 4$ of the perpetrators were friends or relations; $17 \%$ were the (ex-)partners. In $2 / 3$ of the cases the assault occurred in the private sphere. Tables 1 and $\mathbf{2}$ summarise the details reported by the afflicted women about the crime scene, the suspected culprit as well as the course of events.

\section{Traces and injury pattern}

- Table 3 presents an overview of the injuries to the assaulted women as documented in the MFF.
Table 2 Details of crime as reported by the victim $(n=270)$.

\begin{tabular}{|lrr|}
\hline Course of events & n & \multicolumn{1}{c}{$\%$} \\
Vaginal penetration & 161 & $59.6 \%$ \\
\hline yes & 12 & $4.4 \%$ \\
\hline no & 8 & $3.0 \%$ \\
\hline attempted & 75 & $27.8 \%$ \\
\hline - don't know & 7 & $2.6 \%$ \\
\hline - digital & 7 & $2.6 \%$ \\
\hline - no information & & \\
\hline Oral penetration & 53 & $19.6 \%$ \\
\hline yes & 122 & $45.2 \%$ \\
\hline - no & 2 & $0.7 \%$ \\
\hline attempted & 76 & $28.1 \%$ \\
\hline - don't know & 0 & $0.0 \%$ \\
\hline digital & 17 & $6.3 \%$ \\
\hline - no information & & \\
\hline Anal penetration & 39 & $14.4 \%$ \\
\hline - yes & 125 & $46.3 \%$ \\
\hline - no & 10 & $3.7 \%$ \\
\hline attempted & 83 & $30.7 \%$ \\
\hline - don't know & 3 & $1.1 \%$ \\
\hline - digital & 10 & $3.7 \%$ \\
\hline - no information & & \\
\hline Choking/throttling/strangulation & 33 & $12.2 \%$ \\
\hline - yes & 163 & $60.4 \%$ \\
\hline - no & 27 & $10.0 \%$ \\
\hline - don't know & 47 & $17.4 \%$ \\
\hline - no information & & \\
\hline
\end{tabular}

Table 3 Frequency and severity of the documented injuries, categorised according to the modified "clinical injury score" after McGregor et al. [12] $(n=270)$.

\begin{tabular}{lrr}
$\begin{array}{l}\text { Injuries according to the “clinical injury score” } \\
\text { Total }\end{array}$ & n \\
\hline no injury documented & 84 & $31.1 \%$ \\
\hline minor injury/pain & 142 & $52.6 \%$ \\
\hline moderate injury & 31 & $11.5 \%$ \\
\hline serious injury/indication for strangulation & 11 & $4.1 \%$ \\
\hline no association & 2 & $0.7 \%$ \\
\hline Genital injuries & & \\
\hline no injury documented & 213 & $78.9 \%$ \\
\hline minor injury/pain & 28 & $10.4 \%$ \\
\hline moderate injury & 29 & $10.7 \%$ \\
\hline Injuries in ENT region & & \\
\hline no injury documented & 198 & $73.3 \%$ \\
\hline minor injury/pain & 48 & $17.8 \%$ \\
\hline moderate injury & 14 & $5.2 \%$ \\
\hline serious injury/indication for strangulation & 10 & $3.7 \%$ \\
\hline
\end{tabular}

\section{Care situation}

On average the waiting time between formal admission in the emergency department and receiving medical attention amounted to 58 minutes $(\mathrm{n}=240, \mathrm{~min} .0 .0 \mathrm{~h} / \mathrm{max}$. $6.18 \mathrm{~h})$. In more than half of the cases $(58.1 \%, 157 / 270)$ examination and treatment were carried out as desired by a female physician. The so-called medical engagement time amounted on average to $55 \mathrm{~min}(\mathrm{n}=238$, $\mathrm{min} .12 \mathrm{~min} / \mathrm{max} .2 .56 \mathrm{~h}$ ). The responsible nursing staff spent on average $1 \mathrm{~h} 48$ minutes for the care of the patient or, respectively, assistance in the medical examination and diagnosis $(\mathrm{n}=105$, min. $0.30 \mathrm{~h} / \max .6 .30 \mathrm{~h})$. 


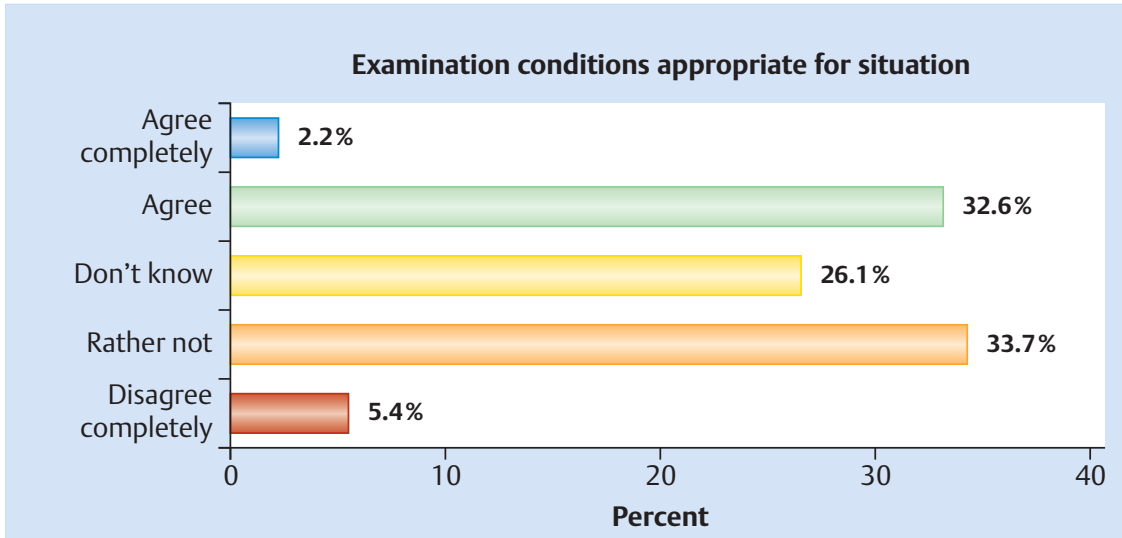

Fig. 1 Evaluation of the examination conditions by the participating personnel (values in $\%, n=92$ ).

Fig. 2 Mental stress for the personnel beyond working hours, opinions of the involved nursing staff and physicians (value in $\%, n=92$ ).

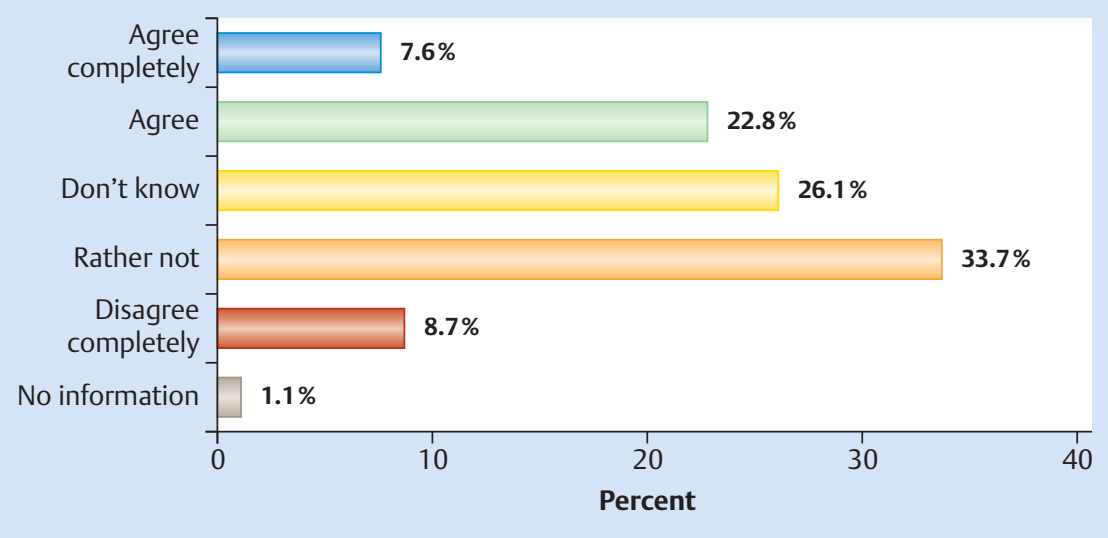

Altogether over half of the patients $(54.4 \%, 147 / 270)$ received further treatment in another specialist department (infectiology, internal medicine, traumatology, ENT etc.) following admission to the emergency department with examination and treatment by physicians of the gynaecology department. In further $26.7 \%$ (72/270) indications for further treatment or consultation were documented in the MFF.

\section{Post-exposure prophylaxis}

After the indication for emergency contraception had been checked in all patients, 53\% (143/270) of them received the "morning-after pill" or a prescription for it. In 35.6\% (96/270) no emergency contraception was initiated, in part because regular contraceptive measures had been reported, the patient was already menopausal or the examination revealed that vaginal penetration had not occurred. $4.1 \%(11 / 270)$ of the patients rejected the emergency contraception and in $7.4 \%$ of the cases no information was available on this subject. Primary post-exposure prophylaxis (PEP) against HIV, hepatitis B and tetanus was administered to $15.2,10$ and $8.1 \%$, respectively, of the patients.

\section{Acquisition of evidence}

Evidence was secured by means of a smear test from the body of the victim in almost all cases (96.3\%).

\section{Personnel survey}

Because of the in part high personnel fluctuation in the emergency departments and the only sporadic utilisation of the emergency departments by victims of sexual violence, the total number of users of the kit in the investigated period cannot be given. 92 members of the Charite emergency departments took part in the personnel survey. Of these 65.2\% (60/92) were nursing staff, $19.6 \%$ (18/92) assistant physicians of the gynaecology departments and $15.2 \%$ (14/92) consultants for gynaecology and obstetrics. $70.7 \%$ (65/92) of the participants were female. The response rate for the medical staff of the gynaecology departments was $78.0 \%$ that for the nursing staff $61.9 \%$. The global concept of the "stuprum kit" was considered by $79.4 \%$ of the participants to be "good" or "very good". 49\% of the participating personnel felt that their preparation for counselling the victims of sexual abuse was "good" or "very good", and $59.8 \%$ felt the same about securing evidence. $34.8 \%$ of the participants considered the examination conditions for the affected women to be suitable for the situation whereas 39.1\% disagreed ( Fig. 1). Different opinions were also seen for the question if the work with victims of sexual abuse also led to mental distress even outside of working hours: about $1 / 3$ answered this question with "yes", $1 / 4$ of the participants were "undecided" and round $40 \%$ reported being "rather not" or "not at all" stressed outside of working hours ( Fig. 2). Two thirds of the participants expressed the wish for supportive measures such as supervision and further training. 


\begin{tabular}{|c|c|c|}
\hline \multicolumn{3}{|c|}{ medical findings form, 6 pages } \\
\hline \multicolumn{3}{|c|}{ - label sheet (for each examination step + blank adhesive labels) } \\
\hline \multicolumn{3}{|c|}{ sheet with self-adhesive seals } \\
\hline \multicolumn{3}{|c|}{ blood, urine and microbiological examination tubes come from the stocks of the Charité } \\
\hline Step 1 & swab oral & - 2 self-drying swab tubes \\
\hline \multirow[t]{3}{*}{ Step 2} & clothes & - 2 paper bags size $X L$ \\
\hline & & - 2 paper bags size $M$ \\
\hline & & - 2 paper bags size $S$ \\
\hline \multirow[t]{3}{*}{ Step 3} & traces on the body & - 3 self-drying swab tubes \\
\hline & & - 2 paper bags size $\mathrm{S}$ (gummed up hair, sanitary towels, panty liner) \\
\hline & & - 1 paper bag size $\mathrm{M}$ (foreign bodies, other traces) \\
\hline Step 4 & photo documentation & - 1 folding ruler $90^{\circ}$ angle, $10 \mathrm{~cm}$ per arm \\
\hline \multirow[t]{11}{*}{ Step 5} & gynaecological examination & - 2 paper bags size $\mathrm{S}$ (clotted/combed out pubic hair, tampon) \\
\hline & of female victims & - 5 self-drying swab tubes \\
\hline & & $1 \times$ outer genitalia \\
\hline & & - $1 \times$ anterior vaginal vault \\
\hline & & - $1 \times$ posterior vaginal vault \\
\hline & & - $2 \times$ cervical canal \\
\hline & & $1 \mathrm{comb}$ \\
\hline & & - 1 ampoule distilled water \\
\hline & genital examination of male victim & 1× glans, sulcus coronarius, penis shaft \\
\hline & & $1 \times$ penile root and scrotal skin \\
\hline & & - 1 ampoule distilled water \\
\hline \multirow[t]{3}{*}{ Step 6} & anus and rectum & - 4 self-drying swab tubes \\
\hline & & - $2 \times$ anus \\
\hline & & $2 \times$ rectum \\
\hline
\end{tabular}

\section{Discussion}

Sexual violence is a major health-care political problem worldwide. The first contact with the health-care system paves the way for the further courses - not only for the salutogenesis of the victim but also for the forensic processing.

The present investigation illustrates a practically complete documentation of 270 cases in which the women, after making a police report about sexual violence, were treated and examined with the help of the "Charité stuprum kit" at one of the three departments of emergency medicine of the Charité (Table 4). First of all, two possible surrogate parameters for patient-friendly treatment should be mentioned. The long waiting times for the patients of about 1 hour on average can be explained by the generally high patient volume in the emergency departments and the usual priority-setting; patients were triaged on the basis of the Manchester triage system (MTS), and were then treated according to urgency. Thus, life-threatening diseases and the classical somatic emergencies are treated first. The long overall management and treatment times arose, among others, due to additional consultations or complicated examination conditions for patients with diminished vigilance, for example, after drug consumption or those in poor mental states that required additional expenditure of time. The relatively low number of post-exposure prophylactic (PEP) measures is due to the fact that here only the treatments primarily performed by the gynaecologists are presented. The results of later consultations in the departments of inner medicine or infectiology are often not included in the present statistics. Examinations by a physician of the same sex as a second surrogate parameter could only be realised in a little more than half of the cases.

It is noteworthy that a large proportion of the perpetrators were reported by the victim to be "strangers". This is due, among other things, to the way the question is posed in the MFF. Here the sus- pected perpetrators are also recorded as "strangers" when the victims had first met them in the hours before the assault. In addition, the prerequisite of a police report prior to management with a "Charité stuprum kit" may serve as a possible selection criterion since a larger inhibitory threshold may be assumed when reporting against a previously known perpetrator.

The treating personnel evaluated the "stuprum kit" including the management and interviewing guidelines predominantly as good to very good. Above all the examination conditions were criticised, thus almost $40 \%$ of the participants considered the situation to be not or rather not appropriate. Considering the importance of an adequate and empathic primary care for victims of sexual violence, a calm and secure environment for the examination of victims should be aimed for. However, for organisational reasons this is difficult to achieve in a hospital emergency department. An improvement in patient-oriented care could be realised by personnel changes with regard to the guaranteed provision of medical staff of the same gender as the victim. Furthermore, less time pressure would certainly have a positive effect on the empathy of the treating personnel and thus on the trusting relationship between the physician and the patient as well as that between nursing staff and patient. This argues in favour of even if it is not easy to achieve organisationally - a duty rostering that takes the victims of sexual violence as a patient group into consideration from the outset. Against the background of the ever increasing overcrowding of emergency departments [13] with, in part, critical care situations for life-threatened patients such special provisions are, however, less realistic.

Even if most of the personnel judge their individual personal burdens beyond working hours that arise from the care of victims of sexual violence to be of "rather no" importance or as "don't know", it must be assumed in general that the care of victims of violence is indeed a burden for the care-giving personnel. Studies confirm that nursing personnel in emergency departments suffer 
more often from stress and burnout than other nursing staff [5, 14]. In a survey of the specialised nursing staff in a US American victim's outpatient department, over half of the participants reported on indirect traumatisation resulting from the treatment of rape victims. The emotional challenges and worries about the victims after they have left the outpatient department were burdens for most of the participants [14]. Also. the role conflict of simultaneously being an empathic person of trust as well as an objective and forensically correct working reporter of findings is not to be underestimated $[15,16]$. Thus, it is not surprising that over $2 / 3$ of the participants in this survey expressed the desire for supportive measures such as supervision and further training in the care of rape victims.

The present study investigating the female victims of sexual violence in a clinical context encompasses a relatively large collective of 270 patients and covers the entire two-year survey period since introduction of the structured "stuprum kit". The healthcare situation is examined from various aspects by evaluation of the medical findings form (MFF), complemented by a survey of the involved personnel. However, this is still a monocentric survey (one hospital, three locations). On account of the high fluctuation, the entire medical and nursing staff of the emergency departments could not be included here and a selection effect cannot be discounted. The involved female patients were not asked to evaluate the health-care situation for ethical and practical reasons.

\section{Conclusions}

\section{$\nabla$}

The more or less complete documentation of the medical findings form included in the "stuprum kit" and the positive evaluation of "stuprum kit" by the personnel illustrate the acceptance and practical utility of this standardised procedure. In the framework of patient-centred health-care without time pressure and long waiting times, however, beside the regular guarantee for medical personnel of the same sex, the increased expenditure of time for the care of victims of sexual abuse should be taken into consideration in the duty rosters of the treating personnel. In consideration of the diverse negative sequelae of sexual violence, the expectations of the victims concerning the health-care environment that have been demonstrated in other studies as well as their perception by the personnel, the prerequisite of a police report for the structured management by means of the "stuprum kit" needs to be questioned. In its place, the now established procedure could be coupled to a comprehensive legal clarification for the affected women with a low threshold and the offer of a socalled confidential securing of evidence which has now also been possible in Berlin since July 1, 2016. In future, attention should also be directed to psychosocial care of the victims.

\section{Acknowledgements}

We are especially grateful to Ms. Dagmar Reinemann, central representative for protection against violence in the Charité, and Dr. Heike Göllner for their support.

\section{Conflict of Interest}

\section{$\nabla$}

The authors report that there are no conflicts of interest concerning the article (see above) submitted to the journal Geburtshilfe und Frauenheilkunde.

\section{Affiliations}

${ }^{1}$ Klinik für Kinder- und Jugendmedizin, Klinikum Westbrandenburg, Medizinische Hochschule Brandenburg Theodor Fontane, Brandenburg a. d. Havel, Germany

2 Notfallmedizin/Rettungsstellen und CPUs, Campus Virchow-Klinikum und Campus Mitte, Charité-Universitätsmedizin Berlin, Berlin, Germany

${ }^{3}$ Gewaltschutzambulanz, Charité - Universitätsmedizin Berlin, Berlin, Germany

${ }^{4}$ Klinik für Gynäkologie, Campus Virchow-Klinikum, Charité - Universitätsmedizin Berlin, Berlin, Germany

\section{References}

1 Müller U, Schröttle M. Lebenssituation, Sicherheit und Gesundheit von Frauen in Deutschland. Eine repräsentative Untersuchung zu Gewalt gegen Frauen in Deutschland. Online: http://www.bmfsfj.de/ RedaktionBMFSFJ/Abteilung4/Pdf-Anlagen/langfassung-studie-frauen -teil-eins,property=pdf,bereich=bmfsfj,sprache=de,rwb=true.pdf; last access: 10.04 .2015

2 FRA - Agentur der Europäischen Union für Grundrechte. Gewalt gegen Frauen: eine EU-weite Erhebung. Ergebnisse auf einen Blick. Online: http://fra.europa.eu/sites/default/files/fra-2014-vaw-survey-at-aglance-oct14_de.pdf; last access: 10.05.2015

3 Kilpatrick DG, Resnick HS, Ruggiero KJ et al. Drug-facilitated, Incapacitated, and Forcible Rape: A National Study. Online: https://www.ncjrs. gov/pdffiles1/nij/grants/219181.pdf; last access: 15.03.2015

4 American College of Obstetricians and Gynecologists. Sexual Assault. Committee Opinion. Obstet Gynecol 2014; 123: 905-909

5 Hagemann-White C, Bohne S. Versorgungsbedarf und Anforderungen an Professionelle im Gesundheitswesen im Problembereich Gewalt gegen Frauen und Mädchen. Universität Osnabrück. 2003. Online: http:// www.cahrv.uni-osnabrueck.de/reddot/gewalt_expertise_ endfassung2.pdf; last access: 14.06.2015

6 Hornberg C, Schröttle M, Bohne S et al. Gesundheitliche Folgen von Gewalt unter besonderer Berücksichtigung von häuslicher Gewalt gegen Frauen. Gesundheitsberichterstattung des Bundes, Heft 42. Berlin: Robert Koch-Institut; 2008

7 Golding JM, Wilsnack SC, Learman LA. Prevalence of sexual assault history among women with common gynecologic symptoms. Am J Obstet Gynecol 1998; 179: 1013-1019

8 Du Mont J, White D, McGregor MJ. Investigating the medical forensic examination from the perspectives of sexually assaulted women. Soc Sci Med 2009; 68: 774-780

9 Jina R, Jewkes R, Munjanja SP et al. Report of the FIGO Working Group on Sexual Violence/HIV: Guidelines for the management of female survivors of sexual assault. Int J Gynecol Obstet 2010; 109: 85-92

10 Campbell $R$. Rape survivors' experiences with the legal and medical systems: do rape victim advocates make a difference? Violence Against Women 2006; 12: 30-45

11 Denis $C$, Seyller $M$, Chariot $P$. Expectations and perceptions of care among victims of sexual assault who first seek care from emergency, primary care and gynaecological doctors. Emerg Med J 2016; 33: 134-138

12 McGregor MJ, Le G, Marion S et al. Examination for sexual assault: Is the documentation of physical injury associated with the laying of charges? A retrospective cohort study. CMJA 1999; 160: 1565-1569

13 Searle J, Muller R, Slagman A et al. Emergency department crowding. Notfall Rettungsmed 2015; 18: 306-315

14 Maier SL. The emotional challenges faced by Sexual Assault Nurse Examiners: "ER nursing is stressful on a good day without rape victims". J Forensic Nurs 2011; 7: 161-172

15 McGregor MJ, Du Mont J, White D et al. Examination for sexual assault: evaluating the literature for indicators of women-centered care. Health Care Women Int 2009; 30: 22-40

$16 \mathrm{Du}$ Mont J, Parnis $D$. The doctor's dilemma: caregiving and medicolegal evidence collection. Med Law 2004; 23: 515-529 